\title{
Endoscopic submucosal dissection of a duodenal GI stromal tumor assisted by endoloops
}

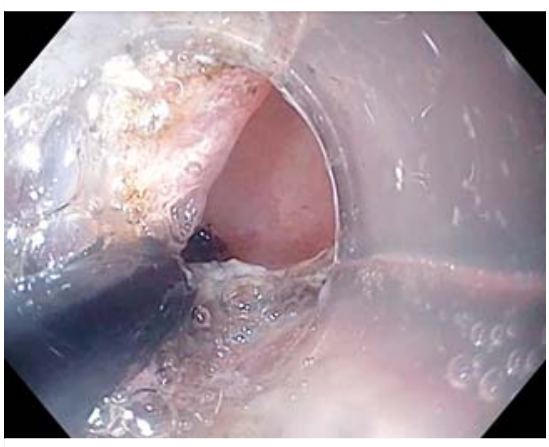

- Fig. 1 The ITknife2 electrosurgical knife was used to dissect the lesion away from the duodenal wall.

A 50-year-old man presented with melena, discomfort, burning, and indigestion associated with intermittent gastric outlet obstruction. Esophagogastroduodenoscopy (EGD) revealed a 4-cm pedunculated polyp extending from the pylorus to the duodenal bulb. In this case we performed a resection of the duodenal polyp using endoscopic submucosal dissection (ESD) assisted by endoloops (Olympus America, Center Valley, Pennsylvania, USA).

First, the lesion was identified endoscopically and the borders were marked circumferentially by placement of two endoloops, which additionally reduced blood supply to the lesion. Next, the base of the lesion was lifted using an injection of methylene blue. After adequate expansion of the submucosal space, the mucosa was incised with the t-type HybridKnife (Erbe, Marietta, Georgia, USA) at the proximal end of the lesion and into the submucosa. A second incision was made at the distal end of the lesion with a hybrid T knife. Using repeated submucosal injections, followed by short bursts of needle knife dissection, the submucosal space of the stalk was dissected. The insulated-tip type-2 knife (ITknife2; Olympus America) was used to dissect the
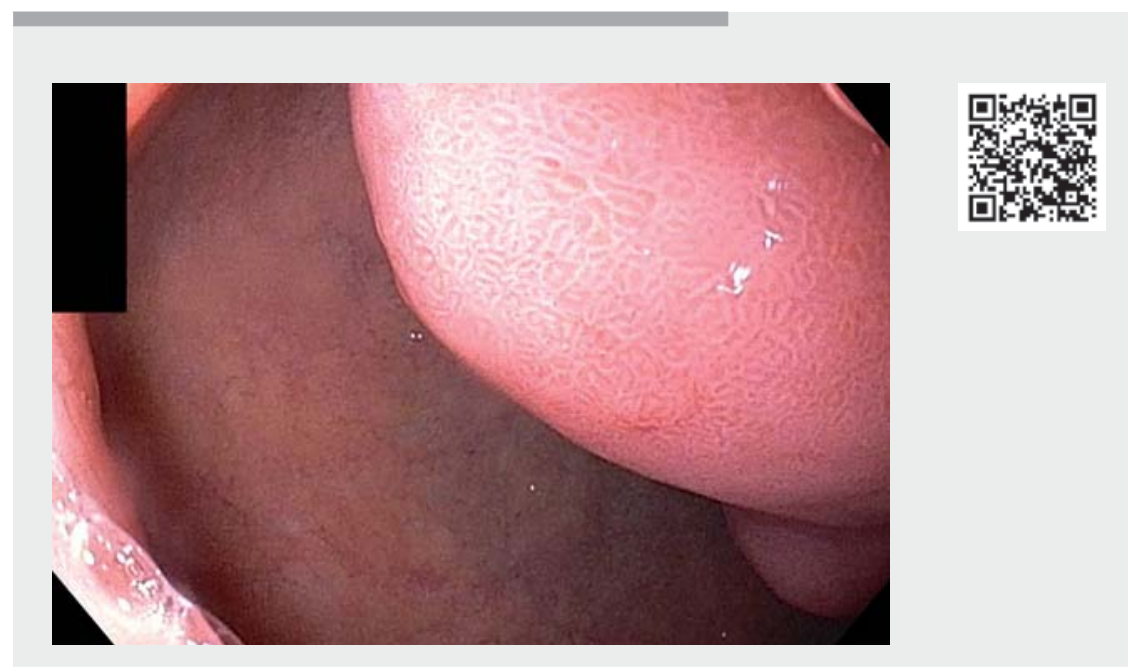

Video 1 A 4-cm pedunculated polyp extending from the pylorus to the duodenal bulb was resected using endoscopic submucosal dissection.

lesion away from the duodenal wall ( $\triangleright$ Fig. 1) ( $\triangleright$ Video 1). It was then extracted from the duodenum en bloc using a hexagonal net (Steris, Mentor, Ohio, USA) and sent for histologic evaluation, which demonstrated a $3.5 \times 2.6 \times 2.7-\mathrm{cm}$ duodenal $\mathrm{Gl}$ stromal tumor. The gastric defect was left open for healing by secondary intention. There were no complications or bleeding at the end of the procedure.

Although ESD of duodenal lesions has an increased risk of complications compared to endoscopic mucosal resection (EMR), the increased rates of complete resection and removal of the lesion en bloc [1] make it a valuable procedure for histologic evaluation of early duodenal neoplasms [2]. ESD is especially useful for larger lesions where it is more difficult for complete resection using EMR [3]. This case demonstrates the successful en bloc resection of a $4-\mathrm{cm}$ duodenal GIST using ESD assisted by endoloops.

Endoscopy_UCTN_Code_CCL_1AB_2AZ_3AB

\section{Competing interests}

Dr Kahaleh has received grant support from Boston Scientific, MaunaKea, Apollo Endosurgery, Cook Endoscopy, ASPIRE Bariatrics, NinePoint Medical, Merit Medical, Olympus, and Interscope Med. Consultant for Boston Scientific, Concordia Laboratories Inc, ABBvie, and MaunaKea Tech.

The authors

Marina Kim, Romy Bareket, Michel Kahaleh $\odot$ Department of Gastroenterology, Robert Wood Johnson Medical Center, New Brunswick, New Jersey, USA

\section{Corresponding author}

\section{Michel Kahaleh, MD}

Department of Gastroenterology, Robert Wood Johnson University Hospital, 1 RWJ Place, MEB 491C, New Brunswick, NJ 08901, USA

mkahaleh@gmail.com 
Bibliography

[1] Perez-Cuadrado-Robles E, Queneherve L, Margos W et al. ESD versus EMR in non-ampullary superficial duodenal tumors: a systematic review and meta-analysis. Endosc Int Open 2018; 6: E998-E1007

[2] Gotoda T, Kaltenbach T, Soetikno R. Is en bloc resection essential for endoscopic resection of GI neoplasia? Gastrointest Endosc 2008; 67: 805-807

[3] Ono H, Kondo H, Gotoda T et al. Endoscopic mucosal resection for treatment of early gastric cancer. Gut 2001; 48: 225-229
Endoscopy 2022; 54: E316-E317

DOI 10.1055/a-1526-0199

ISSN 0013-726X

published online 9.7.2021

(c) 2021. Thieme. All rights reserved.

Georg Thieme Verlag KG, Rüdigerstraße 14, 70469 Stuttgart, Germany

\section{ENDOSCOPY E-VIDEOS}

https:/|eref.thieme.de/e-videos

口回 Endoscopy E-Videos is an open access online section, 靣艘: reporting on interesting cases and new techniques in gastroenterological endoscopy. All papers include a high quality video and all contributions are freely accessible online. Processing charges apply (currently EUR 375), discounts and wavers acc. to HINARI are available.

This section has its own submission website at

https://mc.manuscriptcentral.com/e-videos 